\title{
A Quantitative Study of the Influence of Urban Form on Large-Scale Application of Rooftop Photovoltaics Using Simplified Method
}

\author{
Yutong $\mathrm{Li}^{1}{ }^{1,}$, Kang Jing ${ }^{1}$, Fengrong Liu ${ }^{1}$, Fuyou $\mathrm{Zhao}^{2}$ \\ ${ }^{1}$ Shenzhen Institute of Building Research, CO., LTD., Shenzhen, China \\ ${ }^{2}$ Institute of Refrigeration and Cryogenics, Shanghai Jiao Tong University, Shanghai, China
}

Email address:

aaronleelyt@126.com (Yutong Li)

${ }^{*}$ Corresponding author

To cite this article:

Yutong Li, Kang Jing, Fengrong Liu, Fuyou Zhao. A Quantitative Study of the Influence of Urban Form on Large-Scale Application of Rooftop Photovoltaics Using Simplified Method. International Journal of Sustainable and Green Energy. Vol. 10, No. 2, 2021, pp. 63-75.

doi: $10.11648 /$ j.ijrse.20211002.14

Received: May 29, 2021; Accepted: June 8, 2021; Published: June 16, 2021

\begin{abstract}
The large-scale application of distributed photovoltaic system is often impeded by the shading effect between buildings and mismatch between the solar power generation and building energy consumption. This paper explores the relationship between urban form and rooftop photovoltaic installation and utilization potential with implications for low-carbon city planning. This study first investigated the influence of the urban form on the installation potential of the solar rooftop photovoltaics for 12 cities across China which covering different solar climate zones. The significant impact of the urban density on the photovoltaic installation potential is only observed in the cities in high latitude areas with medium solar radiation, and the negative impact can be mitigated by reducing the building height differences, which up to $25 \%$ improvement can be expected. Then, taking Shenzhen as an example, the influence of the urban form on the photovoltaic power generation utilization was further investigated for residential, commercial and office type of district building energy consumption profiles. It is found that the densely developed urban built-up environment has positive effect on the solar power utilization in which high percentage of the self-consumption ratio is observed. The self-consumption ratio of the residential district which is the lowest can be effectively improved by mixing with office and business buildings. For typical urban form in Shenzhen which the BCR and FAR are 0.35 and 2.5 respectively, if carefully planned, the rooftop photovoltaics can provide $12.6 \sim 18.5 \%$ of the building energy consumption and $69.8 \sim 75 \%$ of the solar power can be directly used by the building, which make the rooftop photovoltaics an important clean and economical energy resource for low-carbon city development.
\end{abstract}

Keywords: Urban Form, Rooftop Photovoltaics, Self-sufficiency Ratio, Self-consumption Ratio

\section{Introduction}

The large-scale application of distributed photovoltaic system in the urban environment is one of the key paths for cities to achieve low-carbon development goals. It can change the structure of urban energy consumption and increase the proportion of clean energy [1-4]. The application of photovoltaics is the most cost-effective way to reduce primary fossil energy use [5]. It is also proved that increasing the number of photovoltaics can reduce primary fossil energy use and global energy costs [6]. According to the analysis of the annual energy structure, $29 \%$ to $75 \%$ of the annual power generation of distributed photovoltaics can be used for self-consumption, which shows the huge potential of distributed photovoltaics in achieving the goal of carbon neutrality [7-11]. However, the shading effect between buildings and mismatch between the solar power generation and building energy consumption often limit the application of the distributed photovoltaic system. Urban form has been proved to be a crucial aspect to modifying the solar 
availability and power generation stability of the photovoltaics in the densely covered city environment [12-16].

Therefore, it is necessary to consider the photovoltaic installation potential in urban planning. The solar radiation on the city's building surface can be accurately simulated, which makes it possible to accurately explore and define the relationship between urban form and solar energy availability. In the previous research, the solar photovoltaic installation potentials of many cities have been investigated on both the individual building and building blocks [10, 12-16]. Several key parameters were identified to study the correlation between urban form and solar energy potential. For example, Poon [10] et al. studied the influence of parameters such as the number of buildings, site coverage (SC), average building height, orientation, and building height differences on photovoltaic power generation and building energy consumption. Ahmadian [12] et al. studied the relationship between the two urban density indicators ( site coverage and volume-area ratio) and urban energy use. However, the mothed developed in previous research are too complex to be used by the urban planners. It is necessary to develop simplified method which can provide the quantitative results.

The random fluctuation of large-scale distributed photovoltaic power generation also brings challenges to the stable operation of the regional electricity grid [17-20]. Eltawil et al. [19] pointed out that the fluctuation of photovoltaic power caused by changes of solar radiation is the main reason for limiting the application of grid-connected photovoltaics. Due to the time deviation between the power generation of the rooftop photovoltaic system and the building load, it cannot be fully consumed, and the surplus power which is connected to the grid will greatly damage the grid stability. Gandhi et al. [20] summarized the grid power quality problems that may occur as the capacity of photovoltaic installed capacity increases, such as harmonics, voltage violations, reverse power flow, and incoordination of grid protection equipment. In order to improve the utilization potential of distributed photovoltaics, it is necessary to integrate the use of distributed photovoltaics into the process of urban planning, and coordinate the urban space planning with the power generation characteristics of photovoltaic renewable energy.

Under this premise, the installation potential of the solar rooftop photovoltaics for 12 cities across China, which covering different solar climate zones, were investigated in this study. The commonly used indicators of urban form such as building coverage ratio (BCR), floor area ratio (FAR) and building height, were used to study the relationship with the photovoltaic installation potential. To better understand the influence of the urban form on the utilization potential of the rooftop photovoltaic system, an simplified quantitative analysis method of the self-consumption and self-sufficiency ratio were further conducted with respect of the district building energy consumption profiles of Shenzhen [21]. This paper provides better understanding of relationship between the urban form and the high proportion of photovoltaics application in the urban environment, and helps making future urban planning decisions.

\section{Methodology}

\subsection{Indicators for Rooftop Photovoltaic Application Potential}

\subsubsection{Indicator for Installation Potential}

Under urban environment, the shading relationship between buildings has a significant impact on the amount of radiation received by the building roof. From an economic point of view, not all the installed solar photovoltaics can generate positive income during its life cycle. If it is heavily shaded, the economic benefits of the photovoltaic system may not cover its initial investment and in turn it economically infeasible. From an environmental perspective, if a photovoltaic system is installed on a heavily shaded roof, the power generation during its life cycle cannot offset the energy consumed during the production process, and the emission reduction during its life cycle may be negative. Therefore, it is necessary to calculate and analyze the annual cumulative radiation amount required for the photovoltaic system to balance the power generation income and initial investment during its life cycle, that is, the economic radiation intensity of solar photovoltaics [9, 11, 22, 23]. In this paper, the economical photovoltaic installation ratio is selected as the index to evaluate the potential of photovoltaic installation capacity in the area, as shown in the following formula:

$$
\vartheta=\frac{A_{R}}{A \delta}
$$

$\vartheta$ The proportion of photovoltaic economic installation, $\%$;

$A-$ Regional site area, $\mathrm{m}^{2}$;

$\delta$-Building coverage ratio $\%$;

$A_{R}$ - The roof area where the annual radiation amount reaches the economic radiation intensity, $\mathrm{m}^{2}$.

The economic radiation intensity in formula (1) is subject to many factors such as photovoltaic conversion efficiency, component life, initial investment and electricity price. In this article, the efficiency of photovoltaic modules is $18 \%$ and the life cycle of photovoltaic modules is 15 years in accordance with "Specification conditions of photovoltaic manufacturing industry" published in 2018 [24]. The initial investment of the rooftop photovoltaic system is the range of $1080 \sim 1800 ¥ / \mathrm{m}^{2}$ and the average unit price is adopted in this study. With these assumptions, the economic radiation intensity of photovoltaics is calculated to be $1112 \mathrm{kWh} /\left(\mathrm{m}^{2} \cdot \mathrm{a}\right)$.

\subsubsection{Indicators for Utilization Potential}

The utilization potential of photovoltaic power generation is generally described by two indicators: self-consumption ratio and self-sufficiency ratio $[13,25]$. The self-sufficiency 
rate $\vartheta^{\prime}$ is the ratio of the amount of photovoltaic power directly used by the building to the total amount of electricity used by the building within a certain period of time; the self-consumption rate $\vartheta^{\prime \prime}$ is the ratio of the amount of photovoltaic power directly used by the building to the total amount of photovoltaic power generation, as shown in the following formula (2) and (3).

$$
\begin{gathered}
\vartheta^{\prime}=\frac{\sum P_{p v, u s e}}{\sum \text { load }} \\
\vartheta^{\prime \prime}=\frac{\sum P_{p v, u s e}}{\sum P_{p v, \text { generate }}}
\end{gathered}
$$

$\vartheta^{\prime}$ - Self-sufficiency rate of photovoltaic power generation, $\%$;

$\sum P_{p v, u s e}$ Photovoltaic power generation which is directly used by buildings, $\mathrm{kWh}$;

$\sum$ load Total electricity consumption of the building, $\mathrm{kWh}$;

$\vartheta^{\prime \prime}$ - Self-consumption rate of photovoltaic power generation, \%;

$\sum P_{p v \text {,generate }}$ The theoretical power generation of the photovoltaic system over a certain period, $\mathrm{kWh}$.

As the random fluctuation of photovoltaic power generation will have a negative impact on the grid stability, priorities should be given to the local consumption of photovoltaic power generation in the building, and the transmission of power to the grid should be reduced as much as possible, that is, the self-sufficiency ratio is the major indicator to evaluate the performance of the large-scale solar photovoltaic application.

\subsection{Indicators for Unban Form}

Urban form generally means the spatial arrangement of various tangible elements in the city. It can be divided into two categories: the horizontal arrangement, such as the type of the land, land area, direction of the roads; and the vertical arrangement, such as building height, building floor area ratio, and building enclosure form [13-15, 26, 27]. This paper selects the building coverage ratio (BCR) and floor area ratio (FAR) that characterize the urban development intensity, as well as the standard deviation of building height that characterizes the vertical arrangement of urban form, as planning control indicators. Besides above indicators, the compatibility mix degree that characterizes the urban land use pattern is further introduced as a planning control indicator for analyzing the utilization potential of distributed photovoltaics. Table 1 shows the definition and calculation method of related indicators.

\subsection{Spatial Model for Urban Form}

In this study, the urban form is illustrated with the representation of a block area on a rectangular grid which represent the city as blocks of varying parameterized heights or properties centered on parcels. The urban cell dimensions of $3 \times 3$ array of buildings was selected as the basic arrangement. The FAR and BCR of the delimited area are used as control parameters. The range of FAR is between 1.0 and 4.0, and the range of $\mathrm{BCR}$ is between $20 \%$ and $45 \%$. The boundary condition settings are shown in Table 2, and the plane layout of different building densities is shown in Figure 1.

\begin{tabular}{|c|c|c|}
\hline Indicator & Indicator definition & Indicator purpose \\
\hline Floor area ratio $(\mathrm{R})$ & $\begin{array}{l}\text { The ratio of the total above-ground building area to the net land area in a } \\
\text { certain region. }\end{array}$ & Characterize land use intensity \\
\hline Building coverage ratio $(\delta)$ & $\begin{array}{l}\text { The ratio of the total base area of buildings to the net land area in a certain } \\
\text { region. }\end{array}$ & $\begin{array}{l}\text { Characterize the degree of building } \\
\text { coverage ratio }\end{array}$ \\
\hline $\begin{array}{l}\text { Standard Deviation of Building } \\
\text { Height }\left(\sigma^{2}\right)\end{array}$ & $\begin{array}{l}\text { Refers to the degree of deviation between the height of each building in a } \\
\text { certain region and the average building height. }\end{array}$ & $\begin{array}{l}\text { Characterize the difference in building } \\
\text { height. }\end{array}$ \\
\hline Compatibility Mix Degree & The proportional relationship between various types of buildings in a region. & $\begin{array}{l}\text { Characterize building energy load } \\
\text { characteristics }\end{array}$ \\
\hline
\end{tabular}

Table 1. Urban form control indicators.

Table 2. Boundary Conditions of Spatial Model.

\begin{tabular}{lllll}
\hline Field length and width $(\mathbf{m})$ & Building length and width $(\mathbf{m})$ & Single-story building height $(\mathbf{m})$ & Building coverage ratio & Floor area ratio \\
\hline & & & $20 \%$ & 1.0 \\
& & $25 \%$ & 1.5 \\
$100 \times 100$ & 3 & $30 \%$ & 2.0 \\
& $22.36 \times 22.36$ & $35 \%$ & 2.5 \\
& & $40 \%$ & 3.0 \\
\hline
\end{tabular}

For each urban cell, once the building layout under different BCRs is settled, the total building area can be determined corresponding to different FARs. The vertical arrangement of the urban cell, which has great impact on the total solar radiation intensity of the building roof, is model by the building height and also the standard deviation of building height $(\sigma 2)$. The greater the standard deviation of building height, the greater the difference in building height, thereby quantifying the complexity of building shading effects. The final spatial model is shown in Figure 2.

\section{Data Input}

\subsection{Representative Cities}

The application potential of solar photovoltaics is not only 
related to the solar radiation intensity, but also the building energy profiles. Therefore, the representative cities were selected according to both building thermal climate zoning and solar climate zone. In terms of building thermal climate zoning, the Chinese national code for thermal design of civil building (GB 50176-2016) defines five building thermal climate zones based on two indicators, namely monthly average minimum temperature and monthly average maximum temperature. The solar climate zones are also defined by the Chinese national standard according to the annual accumulative solar radiation and annual sunshine hours, in which totally five zones are categorized. The representative cities of each climate zone are listed in the Table 3 .

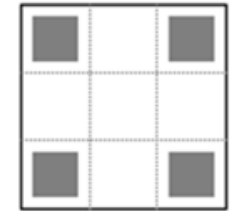

$\delta=20 \%$

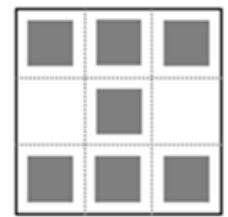

$\delta=35 \%$

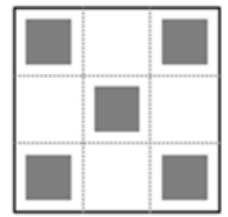

$\delta=25 \%$

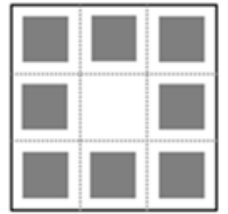

$\delta=40 \%$

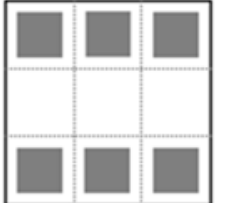

$\delta=30 \%$

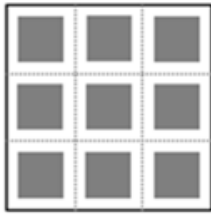

$\delta=45 \%$

Figure 1. The arrangement of different building coverage ratios.

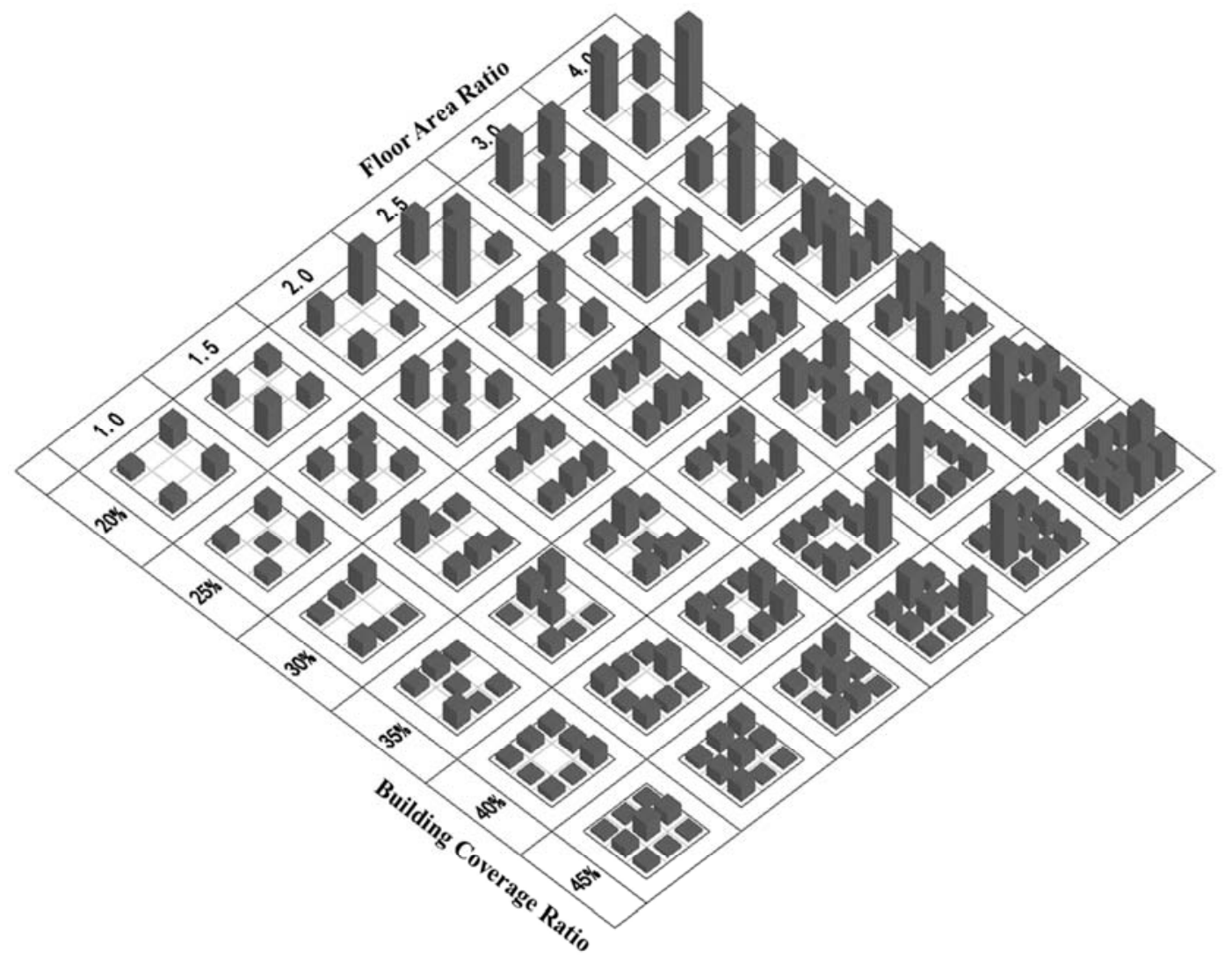

Figure 2. The spatial model for different urban form.

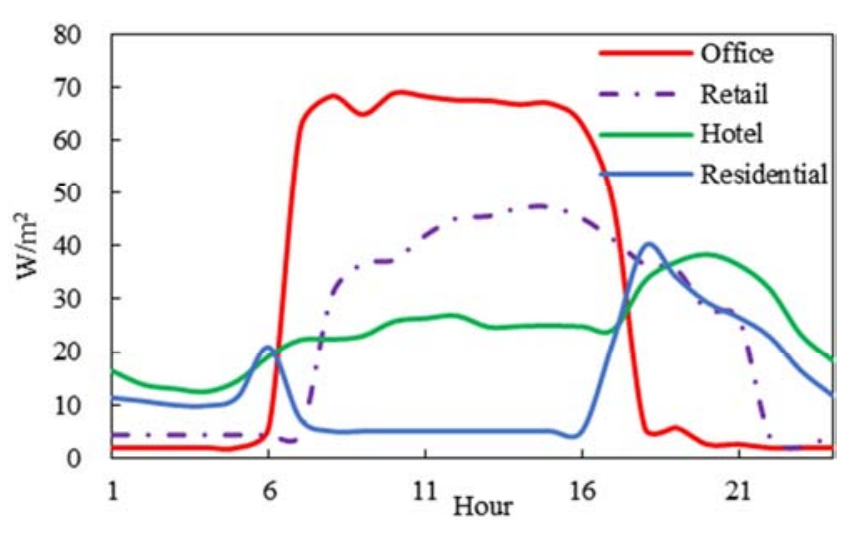

Figure 3. Building hourly load profiles in Shenzhen on summer working day.

\subsection{Building Energy Profiles}

The building types to be analyzed in this article include commercial, office, hotel, and residential building. The energy profile of these building types was simulated using the calibrated Equest building simulation model. These models were calibrated by the actual monitored energy consumption data of Shenzhen building energy monitoring platform in which more than 2400 million square meters' building energy consumption data are collected in this platform. The calibration results show that the monthly, annual error and mean-squared difference coefficient of the simulated energy profile satisfies the requirements of the district level building energy prediction. The details of model settings and calibration process can be found in ref. [21]. Figure 3 shows 
the hourly load curve of various buildings in Shenzhen during typical working days in summer.

Table 3. Representative cities.

\begin{tabular}{|c|c|c|c|c|c|}
\hline \multirow{4}{*}{$\begin{array}{l}\text { Building } \\
\text { Thermal Zone }\end{array}$} & \multicolumn{5}{|c|}{ Solar Climate Zone } \\
\hline & Class I area & Class II area & Class III area & Class IV area & Class V area \\
\hline & $\begin{array}{l}\mathrm{S}>1800 \\
\mathrm{kWh} / \mathrm{m}^{2} \cdot \mathbf{a}\end{array}$ & $\begin{array}{l}1800 \mathrm{kWh} / \mathrm{m}^{2} \cdot \mathbf{a}>\mathrm{S}> \\
1600 \mathrm{kWh} / \mathrm{m}^{2} \cdot \mathbf{a}\end{array}$ & $\begin{array}{l}1600 \mathrm{kWh} / \mathrm{m}^{2} \cdot \mathrm{a}>\mathrm{S}> \\
1400 \mathrm{kWh} / \mathrm{m}^{2} \cdot \mathrm{a}\end{array}$ & $\begin{array}{l}1400 \mathrm{kWh} / \mathrm{m}^{2} \cdot \mathrm{a}>\mathrm{S}> \\
1150 \mathrm{kWh} / \mathrm{m}^{2} \cdot \mathrm{a}\end{array}$ & $\begin{array}{l}1150 \mathrm{kWh} / \mathrm{m}^{2} \cdot \mathbf{a}>\mathrm{S}> \\
930 \mathrm{kWh} / \mathrm{m}^{2} \cdot \mathbf{a}\end{array}$ \\
\hline & $\mathrm{H}>3200 \mathrm{~h} / \mathrm{a}$ & $3200 \mathrm{~h} / \mathrm{a}>\mathrm{H}>3000 \mathrm{~h} / \mathrm{a}$ & $3000 \mathrm{~h} / \mathrm{a}>\mathrm{H}>2200 \mathrm{~h} / \mathrm{a}$ & $2200 \mathrm{~h} / \mathrm{a}>\mathrm{H}>1400 \mathrm{~h} / \mathrm{a}$ & $1400 \mathrm{~h} / \mathrm{a}>H>1000 \mathrm{~h} / \mathrm{a}$ \\
\hline Severe cold area & Golmud & Xining & Urumqi & Harbin & - \\
\hline Cold area & Lhasa & Turpan & Beijing & - & - \\
\hline $\begin{array}{l}\text { Hot summer and } \\
\text { cold winter area }\end{array}$ & - & - & - & Shanghai & Chengdu \\
\hline $\begin{array}{l}\text { Hot summer and } \\
\text { warm winter area }\end{array}$ & - & - & - & Shenzhen & \\
\hline Temperate area & - & Kunming & - & - & Guiyang \\
\hline
\end{tabular}

* "-" in the table indicates that there is no such typical city; "S" is short for Solar radiation intensity; "H" is short for Sunshine hours.

\section{The Influence of Urban Form on Photovoltaic Installation Potential}

The installation potential of 12 cities across China were investigated under different FARs and BCRs. Through preliminary analysis, it is found that the annual solar radiation received by cities in the Class I solar climate zone are always greater than the economic radiation intensity, which means the shading between buildings does not affect the installation capacity of the rooftop photovoltaic system. It can always bring positive benefits during the life cycle, even when the roof is partially covered by the shadow of the conjunction buildings. As in the Class $\mathrm{V}$ solar climate zone, the annual solar radiation $1150 \mathrm{kWh} / \mathrm{m}^{2}$ is less than the economic radiation intensity, even if there is no shelter, it is not suitable to use rooftop photovoltaics. Therefore, the following analysis will focus on the cities in the solar climate zone of class II to $\mathrm{IV}$, with an annual solar radiation level between $1150 \sim 1800 \mathrm{kWh} / \mathrm{m}^{2}$.

Through the simulation analysis of the total horizontal solar radiation intensity of the cities under different urban form, the annual cumulative solar radiation intensity distribution of the roof can be obtained. By counting the proportion of the area where the annual cumulative solar radiation intensity of the roof is greater than the economic solar radiation intensity, the economical installation ratio of the solar roof can be obtained. Figure 4 shows the economical installation ratio of solar photovoltaic roofs in representative cities under different BCRs and FARs.
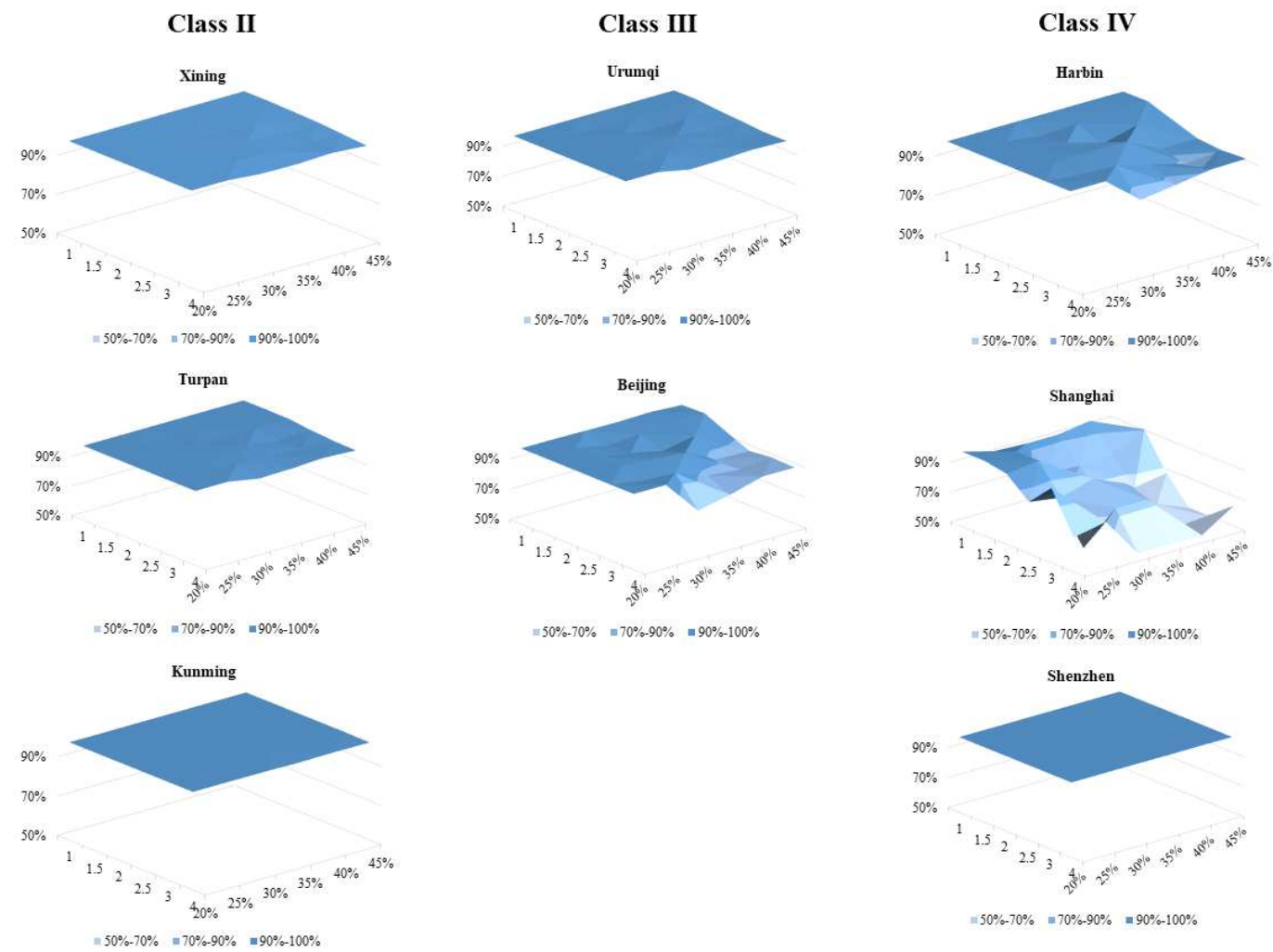

Figure 4. Economical installation ratio of solar photovoltaic roofs under different urban form. 
In general, the greater the regional development intensity is, the severer the shading between buildings becomes. In other words, the bigger the FARs and BCRs are, the smaller the roof area is used for solar PV power generation. But the degree of shading influence varies depending on different solar climate zones and latitude. In class I and II solar climate zone, where the annual solar radiation is strong, the shading between buildings has a smaller impact on PV economical installation ratio, and only makes minor impact when the FAR is greater than 2.5 and BCR is more than $35 \%$. As for Class III and IV areas with relatively small amount of total solar radiation, the shading makes noticeable impact. In the meantime, it is found that the roof economical installation ratio is positively correlated with the solar altitude angle at the same solar climate zone. And that's to say the larger the solar elevation is, the higher the economical installation ratio $\theta^{\prime}$ becomes. The following will further analyze the impact of BCR, FAR and standard deviation of building height on the photovoltaic economic utilization potential.

\subsection{Influence of the Building Coverage Ratio}

When the standard deviation of building height $\sigma 2=30$ and the floor area ratio $\mathrm{R}$ is 4.0 , the economical installation ratio of rooftop photovoltaics $\vartheta$ in different cities varies with BCR $\delta$ as shown in Figure 5 Figure 7. Under the same standard deviation of building height and FAR, the rooftop photovoltaic economical installation ratio is negatively correlate with BCR. The degree of impact of BCR varies greatly among different solar climate zones. For cities in Class II zone, when the BCR is increased from $20 \%$ to $45 \%$, the rooftop photovoltaic economical installation ratio is only reduced by a maximum of $1.5 \%$, while in Class III and IV zones, it is reduced by $10 \%$ and $35 \%$, respectively. Even in the same solar climate zone, the degree of the BCR impact also varies with solar altitude angle. Taking Shanghai and Shenzhen as an example, both of the two cities are located in the Class III solar climate zone. Because the latitude of Shenzhen $\left(22^{\circ} 27^{\prime}-22^{\circ} 52^{\prime}\right.$ north latitude) is lower than that of Shanghai $\left(30^{\circ} 40^{\prime}-31^{\circ} 53^{\prime}\right.$ north latitude), the solar altitude angle is higher, therefore, the economical installation ratio of rooftop photovoltaics in Shenzhen is almost not affected by the shading between buildings, but the situation in Shanghai is the opposite. When the BCR is greater than $35 \%$, only about $50 \%$ of the roof area is suitable for photovoltaic installation.

\subsection{Influence of Floor Area Ratio}

Like the influence of BCR on the economical installation ratio of rooftop photovoltaics, the FAR also negatively correlates with the economical installation ratio. The correlation curves for different cities are shown in Figures $8 \sim 10$. Comparing with the impact of the BCR on the economical installation ratio of rooftop photovoltaics of section 4.1, the influence of FAR is smaller than that of the BCR. The most obvious impact was observed in the class IV cities. Taking shanghai as an example, when increasing the
FAR from 1.0 to 3.0 and also from 3.0 to 4.0 , the economical installation ratio of rooftop photovoltaics decreased by $2 \%$ and $3.7 \%$, respectively. From the perspective of urban planning, the influence in such magnitude is totally neglectable. We may come to the primary conclusion that the high FAR will not barricade the large-scale application of the rooftop photovoltaic system in most of the cities in China.

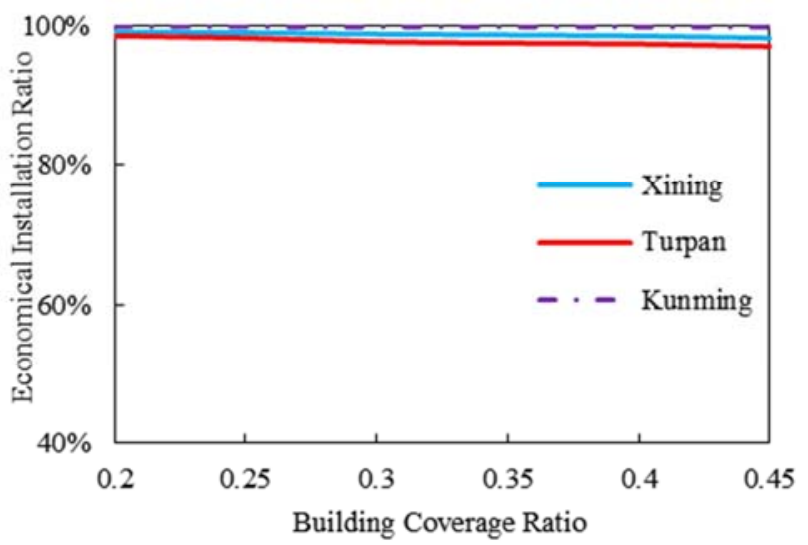

Figure 5. Variation curve of $\theta$ with $\delta$ when $R=4$ for cities in class II solar climate zone.

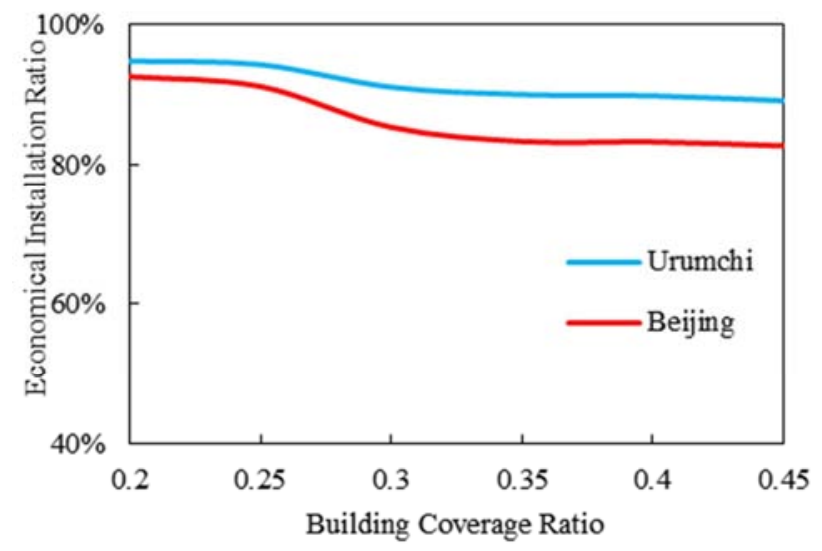

Figure 6. Variation curve of $\theta$ with $\delta$ when $R=4$ for cities in class III solar climate zone.

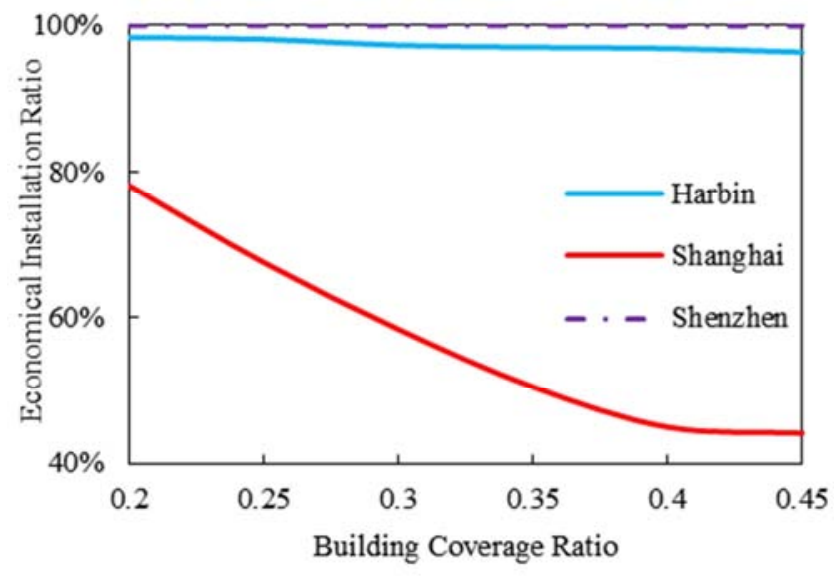

Figure 7. Variation curve of $\theta$ with $\delta$ when $R=4$ for cities in class $I V$ solar climate zone. 


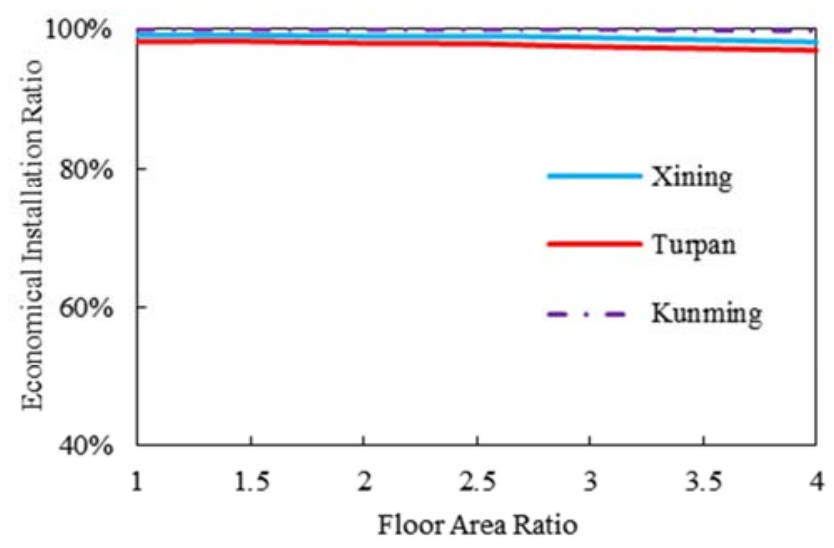

Figure 8. Variation curve of $\theta$ with $R$ when $\delta=45 \%$ for cities in class II solar climate zone.

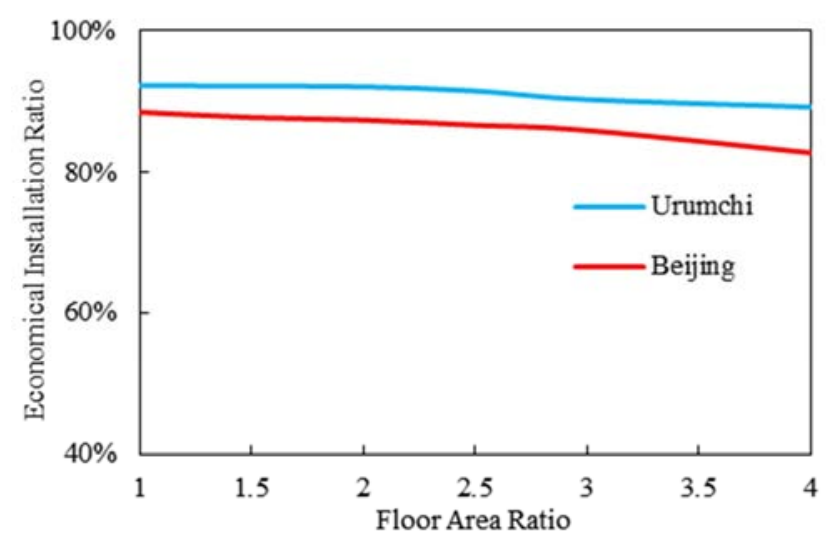

Figure 9. Variation curve of $\theta$ with $R$ when $\delta=45 \%$ for cities in class III solar climate zone.

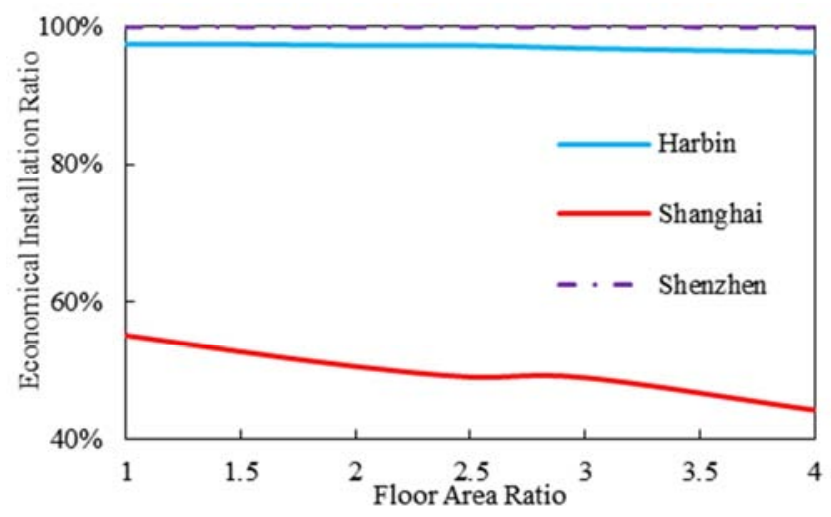

Figure 10. Variation curve of $\theta$ with $R$ when $\delta=45 \%$ for cities in class $I V$ solar climate zone.

\subsection{Influence of the Building Height}

As shown in Figures 11 13, the standard deviation of building height is negatively correlated with the economical installation ratio of rooftop photovoltaics. When the standard deviation of building height changing from 0 to 20, the largest decline in the economical installation ratio of rooftop photovoltaics in class II, III, and IV solar climate zones is $1.6 \%$, $10 \%$, and $25 \%$, respectively. The building height has substantial impact on the rooftop photovoltaic installation potential, particularly to the cities in the class III and IV solar climate zone. Therefore, in the planning stage, balancing the height of regional buildings to avoid mutual shading is an effective way to improve the rooftop photovoltaic utilization potential and increase the power generation of photovoltaic systems.

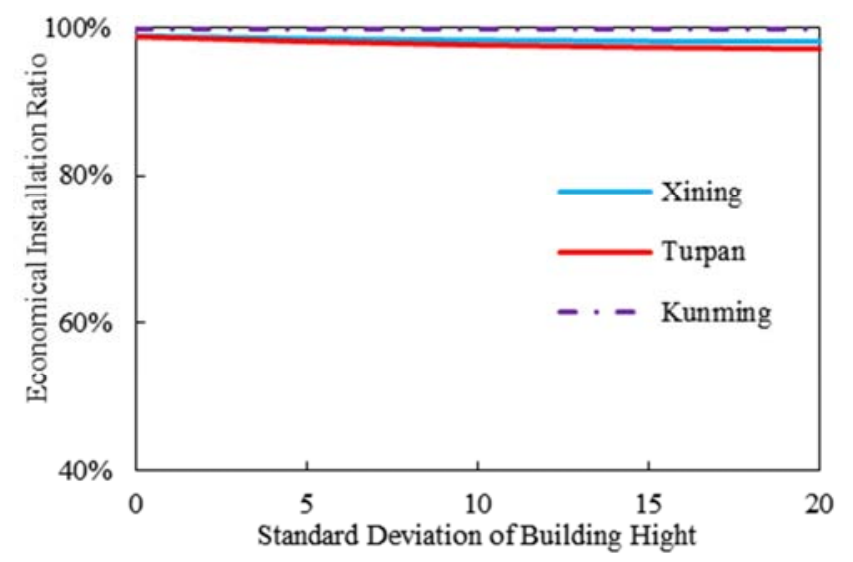

Figure 11. Variation curve of $\theta$ with $\sigma^{2}$ when $\delta=45 \% R=4.0$ for cities in class II zone.

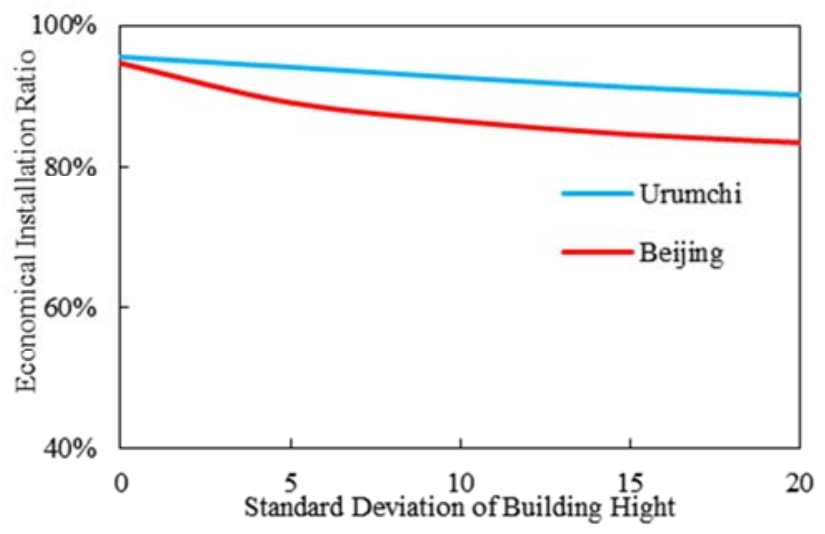

Figure 12. Variation curve of $\theta$ with $\sigma^{2}$ when $\delta=45 \% R=4.0$ for cities in class III zone.

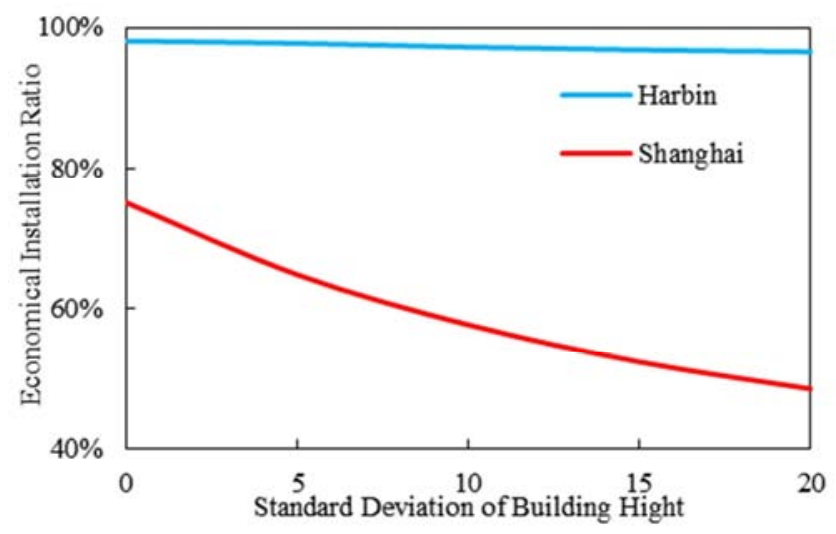

Figure 13. Variation curve of $\theta$ with $\sigma^{2}$ when $\delta=45 \% R=4.0$ for cities in class IV zone.

\section{The Influence of Urban form on the Photovoltaic Power Utilization}

Taking Shenzhen as an example, this section further 
investigated the influence of the urban form on the utilization potential of the rooftop photovoltaic system. The installation capacity was obtained by using the quantitative relationship between the urban form and the economical installation ratio of photovoltaic established in section 4 and the district energy consumption profiles of different urban planning scenarios was simulated using the calibrated Equest model of Shenzhen which is introduced in Section 2. The urban planning scenarios was planned by changing the compatibility mix degree, BCR and FAR. And we use the above model to simulate its annual operation, calculate the photovoltaic self-sufficiency rate and self-consumption rate of different urban planning scenarios, and compare and analyze the impact of urban form on the potential of renewable energy. Three types of the district were studied in this section, namely residential type, commercial type, and office type. Their definitions are listed below.

Residential type: a regional space dominated by residential buildings (the proportion is higher than $60 \%$ ). At the same time, in order to ensure the living needs of residents, some office buildings (such as properties) and commercial buildings (such as supermarkets) are also planned;

Commercial type: a regional space dominated by commercial buildings (the proportion is higher than 60\%), with some office buildings and a small number of residential buildings at the same time;

Office type: a regional space dominated by office buildings (above 60\%), as well as some commercial buildings and a small number of residential buildings.

For each district type, the planning indicators, such as BCR and FAR, can be varied to obtain different scenarios. The ranges of the indicators are listed in Table 4. By solving the above model, the quantitative analysis of the self-consumption and self-sufficiency ratio can be conducted to understand the impact of the urban form on the photovoltaic utilization potential.

Table 4. The planning parameters of different scenarios.

\begin{tabular}{llll}
\hline District type & Building coverage ratio & Floor area ratio & Mixing degree Residence: Commercial: Office \\
\hline Residential type & $25 \sim 35 \%$ & $1.0 \sim 2.5$ & $80 \%: 10 \%: 10 \% \%$ \\
Commercial type & $25 \sim 35 \%$ & $1.0 \sim 2.5$ & $10 \%: 80 \%: 10 \%$ \\
Office type & $25 \sim 35 \%$ & $1.0 \sim 2.5$ & $10 \%: 10 \%: 80 \%$ \\
\hline
\end{tabular}

\subsection{The Impact of Building Coverage Ratio}

The impact of the BCR on the photovoltaic self-sufficiency rate and self-consumption rate of residential area is shown in Figure 14. As expected, the self-sufficiency rate increases with the BCR and the self-consumption rate decreases. For the same building scale, the greater the BCR, the larger the photovoltaic installation area and photovoltaic power generation, which will increase the self-sufficiency rate. And because the mismatch between the solar power generation and residential energy consumption, self-consumption rate will decrease with the increasing BCR.

Figure 15 shows the impact of BCR on photovoltaic self-sufficiency rate and self-consumption rate of commercial areas. It is found that $15.1 \sim 47.1 \%$ of the commercial building

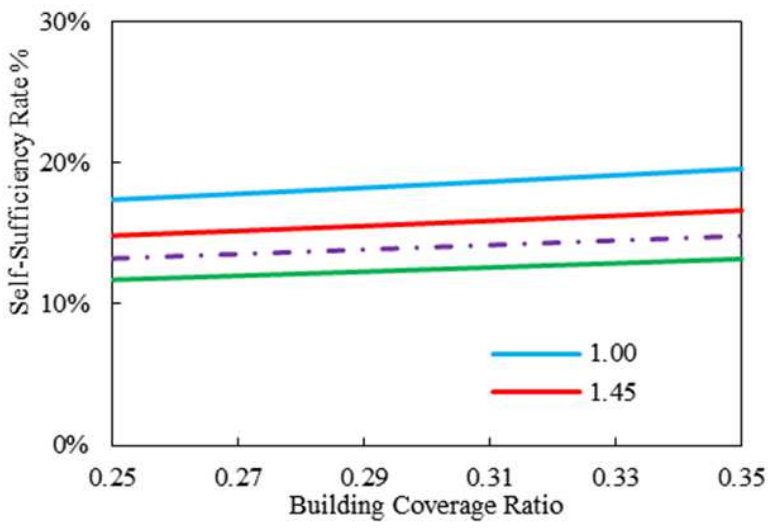

(a) energy consumption can be provided by the rooftop photovoltaic system and most of the solar power can be consumed locally. Comparing with the results of residential area, the self-sufficiency rate and self-consumption rate of commercial area are much higher than that of residential area. The main reason is that the load curve of commercial buildings is more consistent with the photovoltaic power generation curve, so the self-sufficiency rate and self-consumption rate are higher. The highest self-sufficiency rate can reach $47.1 \%$, and the lowest self-consumption rate can also reach $93.0 \%$. The impact of BCR on the utilization of photovoltaic is not significant, especially when the FAR is very high. When the FAR is 2.5 , the self-sufficiency rate is increased by $4 \%$, and the self-consumption rate is hardly affected.

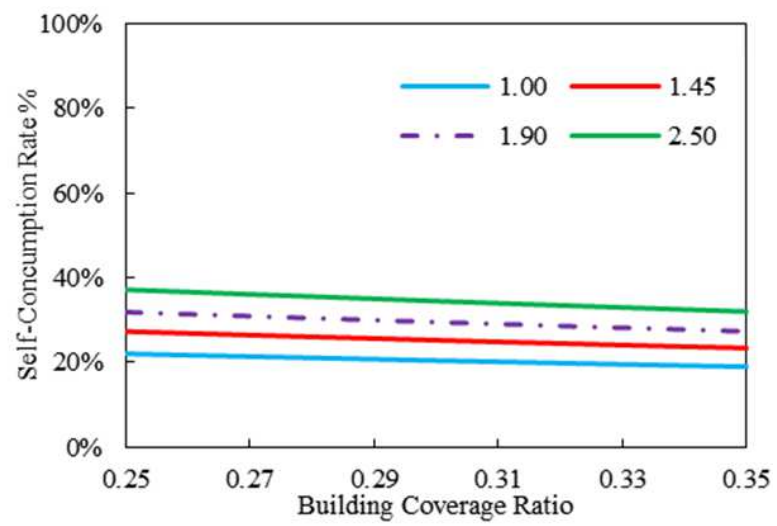

(b)

Figure 14. (a) Self-sufficiency rate and (b) self-consumption rate in residential area. 


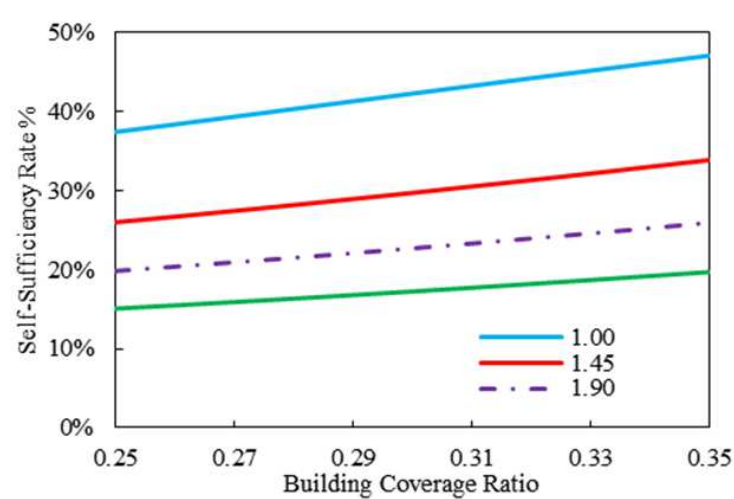

(a)

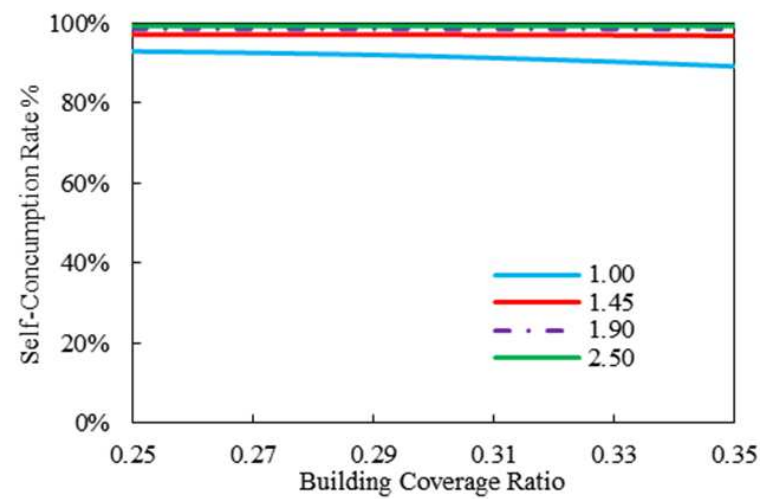

(b)

Figure 15. (a) Self-sufficiency rate and (b) self-consumption rate of commercial area.

As to the business area, its self-sufficiency rate is in the same magnitude of the self-sufficiency rate of the commercial area, which is in the range of $18.5 \sim 50.7 \%$, but its self-consumption rate is lower than that of the commercial area. $14.8 \sim 28.7 \%$ of the solar power cannot be consumed

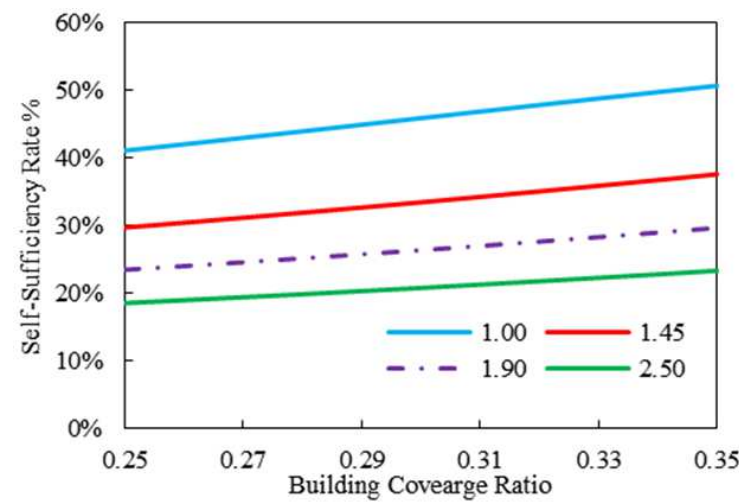

(a) locally. This is because even if office buildings and commercial buildings have similar load curves on working days, but the office building only has base load during weekends and holidays, which will make the annual average self-consumption rate lower than that of the commercial area.

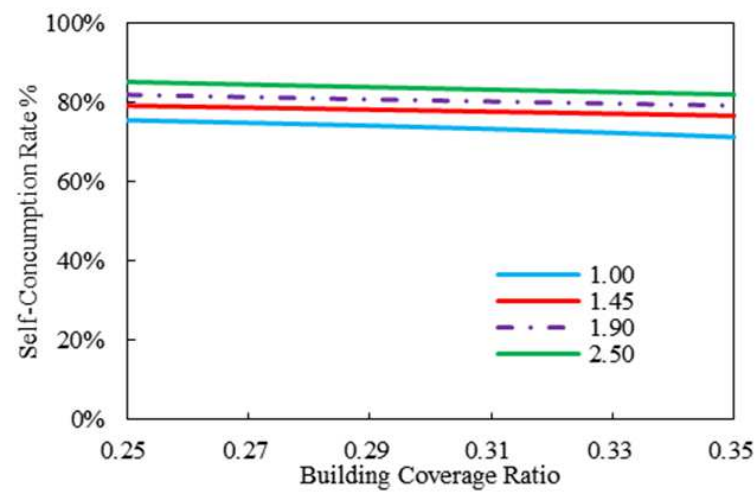

(b)

Figure 16. (a) Self-sufficiency rate and (b) self-consumption rate of office area.

\subsection{The Influence of Floor Area Ratio}

The influence of the FAR on the photovoltaic self-sufficiency rate and self-consumption rate of residential area is shown in Figure 17. It is found that the self-sufficiency rate decreases with the $\mathrm{BCR}$ and the self-consumption rate increases. Comparing with the influence of the BCR, the FAR has greater influence on the solar power utilization. This is

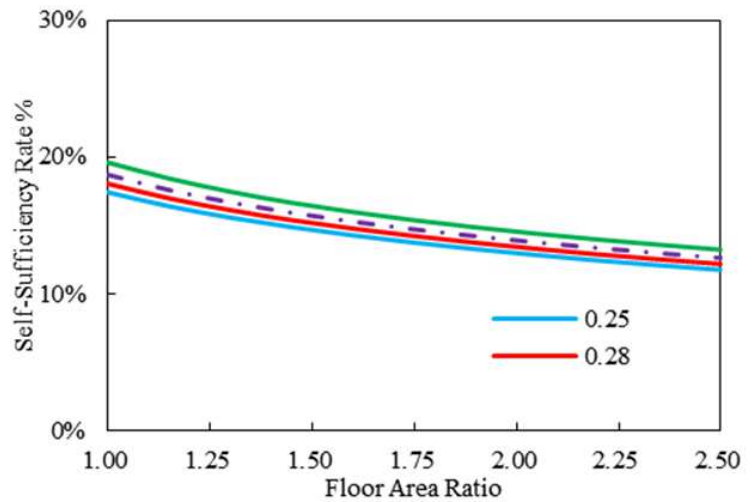

(a) because the larger the FAR means the larger the building load, while the photovoltaic area and power generation do not change, so the increasement of FAR reduces the self-sufficiency rate of photovoltaic power generation and increases the self-consumption rate. It can be seen that the increase in FAR has reduced the self-sufficiency rate by about $7 \%$, and at the same time increased the self-consumption rate by about $13 \%$.

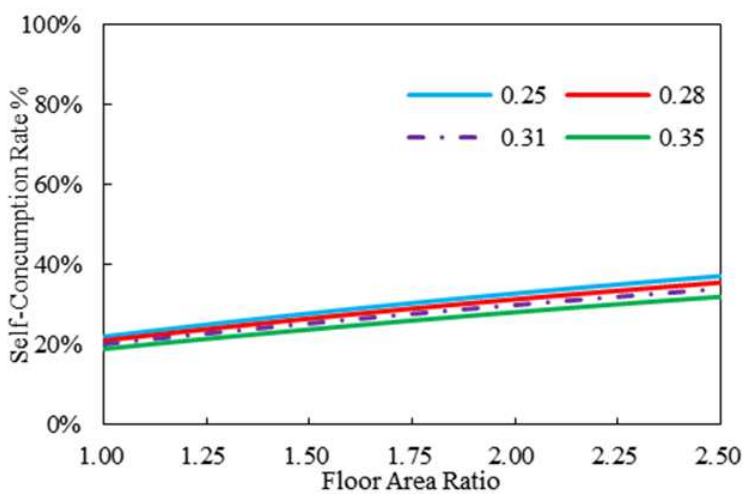

(b)

Figure 17. (a) Self-sufficiency rate and (b) self-consumption rate of residential areas 


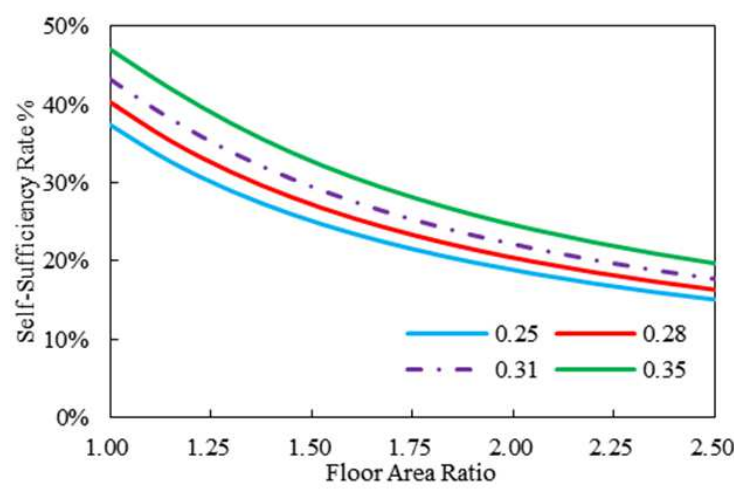

(a)

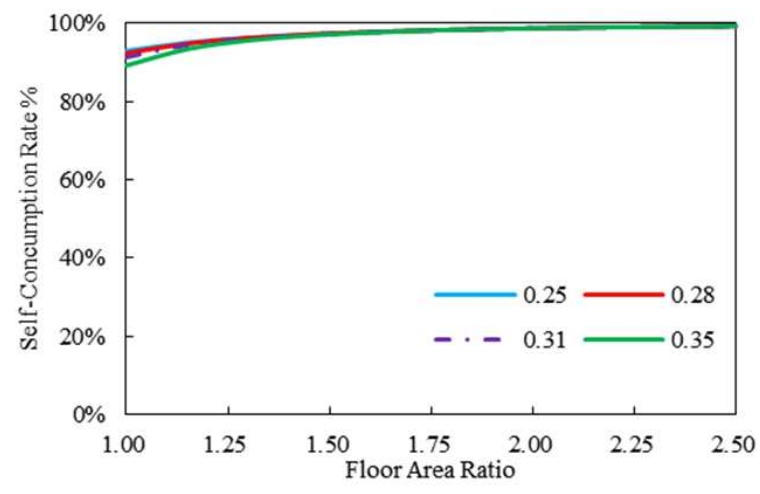

(b)

Figure 18. (a) Self-sufficiency rate and (b) self-consumption rate in commercial areas.

Figure 18 shows how the self-sufficiency rate and self-consumption rate of the commercial area are affected by the FAR. It is found that the photovoltaic utilization of commercial areas is less affected by the FAR than residential areas. This is because the photovoltaic utilization rate of

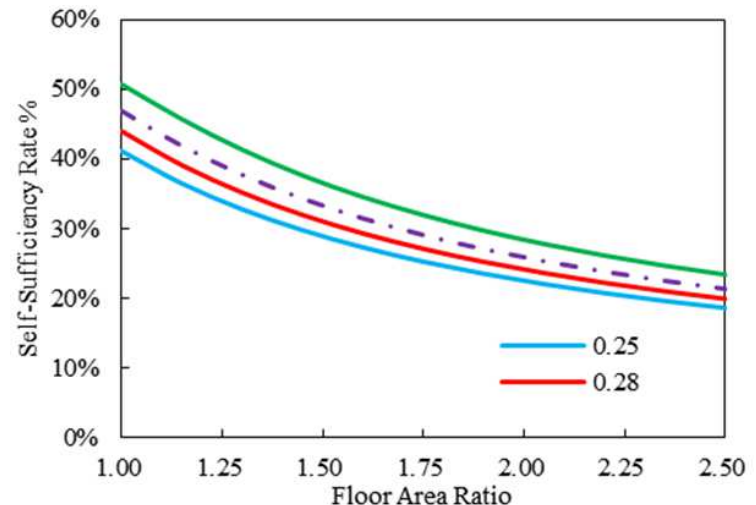

(a) commercial buildings is higher than that of residential buildings, and the increase in building load has little effect on changing this ratio. Therefore, the increase in self-consumption rate is only $7 \%$, which is almost half of that of residential buildings.

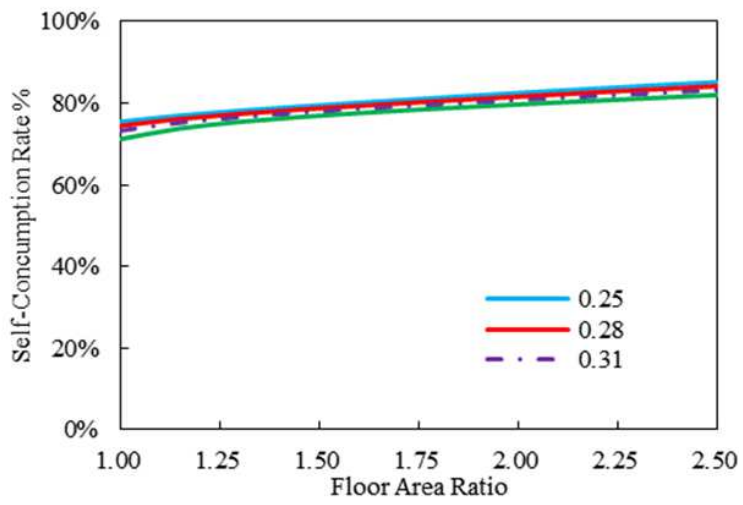

(b)

Figure 19. (a) Self-sufficiency rate and (b) self-consumption rate of office area.

Figure 19 shows that the photovoltaic self-sufficiency rate and self-consumption rate of the office area are affected by the FAR. It is worth mentioning that the self-sufficiency rate of photovoltaics in this area is higher than $20 \%$, and the self-consumption rate is even lower than $80 \%$. It further proves that office buildings waste a lot of photovoltaic power generation when the load on weekends and rest days is small, and the proportion of office buildings can be reduced in planning to increase the self-consumption rate.

\subsection{The Impact of Compatibility Mix Degree}

To study the impact of the compatibility mix degree on the photovoltaic utilization potential, two different combinations of building type are selected for each district type. The compatibility mix degree of each district type are shown in Table 5. Cases 1 and 2 both belong to residential areas, cases 3 and 4 are commercial type, cases 5 and 6 are office type and cases 7 and 8 are mixed type. For all the cases, the FAR is kept at 2.5.

Table 5. The self-sufficiency rate and self-consumption rate of different mix degree.

\begin{tabular}{|c|c|c|c|c|c|c|c|}
\hline \multirow{3}{*}{ Case Number } & \multirow{3}{*}{$\begin{array}{l}\text { Mix degree } \\
\text { Residential: Commercial: } \\
\text { Office }\end{array}$} & \multicolumn{6}{|c|}{ Building coverage ratio } \\
\hline & & \multicolumn{2}{|l|}{0.25} & \multicolumn{2}{|l|}{$\mathbf{0 . 3 0}$} & \multicolumn{2}{|l|}{0.35} \\
\hline & & SSR & SCR & SSR & SCR & SSR & SCR \\
\hline 1 & $80 \%: 10 \%: 10 \%$ & $12.6 \%$ & $49.5 \%$ & $13.1 \%$ & $48.4 \%$ & $13.7 \%$ & $47.3 \%$ \\
\hline 2 & $60 \%: 20 \%: 20 \%$ & $13.6 \%$ & $60.4 \%$ & $14.2 \%$ & $59.5 \%$ & $15.0 \%$ & $58.5 \%$ \\
\hline 3 & $10 \%: 80 \%: 10 \%$ & $14.2 \%$ & $92.5 \%$ & $15.1 \%$ & $92.3 \%$ & $16.1 \%$ & $92.0 \%$ \\
\hline 4 & $20 \%: 60 \%: 20 \%$ & $14.4 \%$ & $84.9 \%$ & $15.2 \%$ & $84.5 \%$ & $16.1 \%$ & $84.1 \%$ \\
\hline 5 & 10\%: $10 \%: 80 \%$ & $16.6 \%$ & $82.7 \%$ & $17.5 \%$ & $82.0 \%$ & $18.5 \%$ & $81.2 \%$ \\
\hline 7 & $33 \%: 33 \%: 33 \%$ & $14.6 \%$ & $75.0 \%$ & $15.4 \%$ & $74.3 \%$ & $16.3 \%$ & $73.5 \%$ \\
\hline 8 & $40 \%: 30 \%: 30 \%$ & $14.4 \%$ & $71.3 \%$ & $15.1 \%$ & $70.5 \%$ & $16.0 \%$ & $69.8 \%$ \\
\hline
\end{tabular}

* SSR: Self-sufficient rate; SCR: Self-consumption rate 


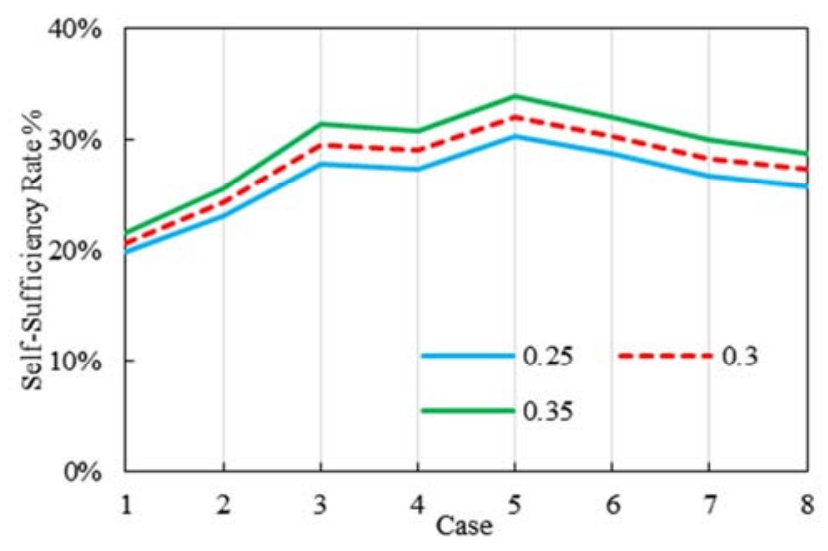

Figure 20. The influence of mix degree on regional $P V$ self-sufficiency rate.

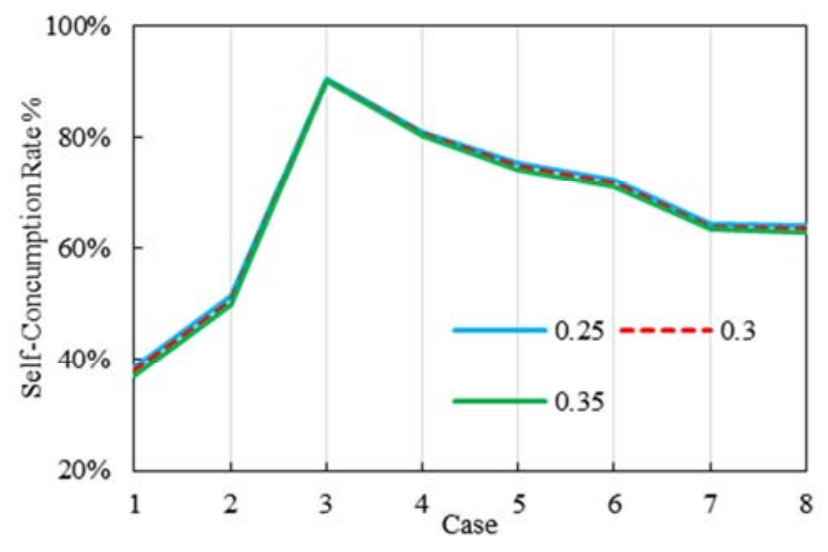

Figure 21. The influence of mix degree on regional $P V$ self-consumption rate.

The influence of the compatibility mix degree on the self-sufficiency rate and self-consumption rate are shown in Figures 20 and 21 . It can be seen that the residential areas have the lowest photovoltaic self-sufficiency rate (case 1 and 2), and by increasing the mix degree of commercial and office building, the self-sufficiency rate can be improved. For the other cases, increasing the compatibility mix degree will not improve the self-sufficiency rate, but the self-consumption rate decreases with the mix degree for most of cases. For example, comparing the two cases of the commercial area (case 3 and 4), both of the self-consumption rate and self-sufficiency rate are decreased when increase the percentage of the office and residential building in the commercial area. This trend may imply that increase the compatibility mix degree is only effective to improve the solar power utilization of the residential area, but for other types of area, it needs further study to qualified the improvement.

\section{Discussions}

Traditionally, urban energy system planning and the urban form planning are two sperate processes. The energy system is planned after the urban form planning, and is simply considered to meet the needs of the energy demand. In the context of low-carbon city development, the renewable energy, especially the large-scale application of the distributed photovoltaic, requires the interactional planning of the urban form and renewable energy system. So, it is necessary to have a clear understanding of the relationship between distributed renewable energy system and urban form. Through this paper, several questions of the large-scale photovoltaic application might be answered.

\subsection{Is Distributed Photovoltaics Suitable to Be Installation in High-density Cities}

Because of the shading effect between buildings, the distributed photovoltaic on the building surface has long been accused for low efficiency and not economical feasible. In this study, we do observe a negative impact of the shading on the rooftop photovoltaic installation capacity. For the 12 cities studied in this research, the economical installation ratio of the rooftop photovoltaic all decrease with the increasing BCR and FAR, but the degrees of decrease are different in different solar climate zones and latitudes. For cities in the Class I and II solar climate zones with solar radiation above $1600 \mathrm{kWh} /\left(\mathrm{m}^{2} \cdot \mathrm{a}\right)$, the impact of shading on the economical installation ratio is generally within $5 \%$. From the view of city or district level planning, the negative impact in such magnitude can be totally tolerated and will not influence the installation capacity at the city level.

However, for other cities in the class III and IV climate zones with annual solar radiation in the range of 1200 1500 $\mathrm{kWh} /\left(\mathrm{m}^{2} \cdot \mathrm{a}\right)$, the negative impact of shading is not negligible, particular for those cities also in the high-latitude area. The maximum impact of the shading observed in this study is up to $55.1 \%$ when the BCR is 0.45 and floor are ratio is 4.0 . We also found that the negative impact of the shading effect can be mitigated by reducing the height difference between buildings. Taking Shanghai as an example, under the same FAR and BCR, the roof area that suitable for photovoltaic installation of an evenly distributed building height case is nearly $25 \%$ higher than that of the randomly distribution.

\subsection{How Much City Energy Demand Can Be Supplied by the Distributed Photovoltaics}

It is usually believed that the distributed photovoltaic in the city environment can only supply a very small portion of the energy demand, because of the limited roof area and high energy demand of the densely urban building. Through the case study of Shenzhen, we found that the distributed rooftop photovoltaics can supply a substantial portion of the city energy demand and the high-density urban form is favorable in terms of solar power self-consumption. According to the simulation results of this article, when the FAR is 2.5 , the self-sufficiency ratio of the rooftop photovoltaics can reach the range of $12.6 \sim 18.5 \%$ for different district types and BCRs, which means this portion of urban energy demand is directly supplied by the solar power. For other cases with lower FAR, the self-sufficiency rate can be even higher. This makes the distributed photovoltaic system an important role in the city energy transformation from the fossil to the renewable energy. 


\subsection{Will the Large-scale Distributed Photovoltaics Causes any Fluctuation in the City Electrical Grid}

It is well known that the random variation of the solar radiation will cause the power fluctuation in the electrical grid when large-scale photovoltaic connected, and makes it hard for the grid to balance the power supply and demand. In the case study of Shenzhen, we found that the high-density urban form is favorable in terms of solar power self-consumption. For the commercial and office type districts, when the FAR is 2.5 , the self-consumption rate can reach $77.9 \sim 92.5 \%$ for different BCRs. For these two types of districts, even when the FAR is 1.0 , their self-consumption rate can still reach more than $71.3 \%$. This means most of the solar power generation is consumed locally and will not feed back to the electrical grid.

For the residential district, the self-consumption rate is relatively lower, because of the mismatch between the solar power generation and residential energy demand. when the FAR is 2.5, its self-consumption rate is in the range of $47.3 \sim 60.4 \%$ for different BCRs. Mixing with other types of building and increasing the compatibility mix degree of the residential area can only make limited improvement, there is still large portion of the surplus solar power. It may imply that the residential district is not the ideal location for the large-scale application of the distributed photovoltaic. For the mixed type district, which may be closer to the actual composition, the self-consumption rate falls in the range of $69.8 \sim 75 \%$ when the FAR is 2.5 . The large-scale application of the distributed photovoltaic will not cause a significant fluctuation in the city electrical grid since most of the solar power is consumed locally.

\subsection{What Kind of Urban Form Is Preferable for the Distributed Photovoltaic Application}

Through this study, we may have some deeper understandings of the relationship between the photovoltaic application potential and the urban form, but it is still not comprehensive enough to draw a conclusion. With findings of this study and related literatures, there several generic suggestions can be made for the urban planners.

The spatial arrangement of the buildings, BCR and building height differences, have a significant impact on the distributed rooftop photovoltaic installation capacity. For cities in a high-latitude location and with relatively lower solar radiation, arranging the building height in an orderly or evenly way is an effective planning method to avoid mutual shading and improve the photovoltaic installation capacity.

The high FAR is not the barrier for the distributed rooftop photovoltaic installation, and it is favorable in terms of local consumption of the solar power. The commercial and business district are the better location to install distributed rooftop photovoltaics than the residential district.

\section{Conclusions}

The large-scale application of the distributed photovoltaics is one the promising way for the low-carbon city development.
However, its application is often impeded by the shading effect between buildings and mismatch between the solar power generation and building energy consumption. This paper explores the relationship between urban form and rooftop photovoltaic installation and utilization potential with implications for low-carbon city planning. This study first investigated the influence of the urban form on the installation potential of the solar rooftop photovoltaics for 12 cities across China which covering different solar climate zones. Then, taking Shenzhen as an example, the influence of the urban form on the photovoltaic power utilization was further investigated for residential, commercial and office type district. The significant impact of the urban density on the photovoltaic installation potential is only observed in the cities in high latitude locations with medium solar radiation, and the negative impact can be mitigated by reducing the building height differences, which up to $25 \%$ improvement can be expected. It is also found that the densely developed urban built-up environment has positive effect on the solar power utilization in which high percentage of the self-consumption ratio is observed. For typical urban form in Shenzhen which the BCR and FAR are 0.35 and 2.5 respectively, if carefully planned, the rooftop photovoltaics can provide $12.6 \sim 18.5 \%$ of the building energy consumption and $69.8 \sim 75 \%$ of the solar power can be directly used by the building, which make the rooftop photovoltaics an important clean and economical energy resource for low-carbon city development.

The results obtained in this research could be used to support the reginal master plan proposals and related urban planning guidelines. For detailed planning, more sophisticated Geographical Information System (GIS) which can provide and process more information of the urban form will be adopted to further study the effect of other factors, such as the green space and topography.

\section{Acknowledgements}

The authors appreciate the financial support provided by the National Key R\&D Program of China for the Research and Development of City Energy Efficiency and Low Carbon Solution Tool Project (Project Number: 2017YFE0105600).

\section{References}

[1] Moosavian, S. M., et al. "Energy policy to promote photovoltaic generation." Renewable and Sustainable Energy Reviews 25 (2013): 44-58.

[2] Hoeven, M. V. D. "Technology roadmap: solar photovoltaic energy." International Energy Agency, Paris, France (2015).

[3] Calvillo, Christian F., Alvaro Sánchez-Miralles, and Jose Villar. "Energy management and planning in smart cities." Renewable and Sustainable Energy Reviews 55 (2016): 273-287.

[4] Jia, Yuting, Guruprasad Alva, and Guiyin Fang. "Development and applications of photovoltaic-thermal systems: A review." Renewable and Sustainable Energy Reviews 102 (2019): 249-265. 
[5] Arumägi, Endrik, and Targo Kalamees. "Cost and Energy Reduction of a New nZEB Wooden Building." Energies 13.14 (2020): 3570 .

[6] Congedo, Paolo Maria, et al. "Efficient solutions and cost-optimal analysis for existing school buildings." Energies 9. 10 (2016): 851.

[7] Singh, Rhythm. "Approximate rooftop solar PV potential of Indian cities for high-level renewable power scenario planning." Sustainable Energy Technologies and Assessments 42 (2020): 100850

[8] Eslami, Hossein, et al. "The potential of urban distributed solar energy in transition economies: The case of Beirut city." Journal of Environmental Management 285 (2021): 112121.

[9] Mangiante, Michael J., et al. "Economic and technical assessment of rooftop solar photovoltaic potential in Brownsville, Texas, USA." Computers, Environment and Urban Systems 80 (2020): 101450.

[10] Poon, Kin Ho, and Jerome Kaempf. "A morphological based PV generation and energy consumption predictive model for Singapore neighborhood." Journal of Physics: Conference Series. Vol. 1343. No. 1. IOP Publishing, 2019.

[11] Ramírez-Sagner, Gonzalo, et al. "Economic feasibility of residential and commercial PV technology: The Chilean case." Renewable Energy 111 (2017): 332-343.

[12] Ahmadian, Ehsan, et al. "Correlation of urban built form, density and energy performance." Journal of Physics: Conference Series. Vol. 1343. No. 1. IOP Publishing, 2019.

[13] Talavera, D. L., et al. "A new approach to sizing the photovoltaic generator in self-consumption systems based on cost-competitiveness, maximizing direct self-consumption." Renewable energy 130 (2019): 1021-1035.

[14] Rodríguez-Álvarez, Jorge. "Urban Energy Index for Buildings (UEIB): A new method to evaluate the effect of urban form on buildings' energy demand." Landscape and Urban Planning 148 (2016): 170-187.

[15] Futcher, Julie Ann, Tristan Kershaw, and Gerald Mills. "Urban form and function as building performance parameters." Building and environment 62 (2013): 112-123.

[16] Boccalatte, A., M. Fossa, and C. Ménézo. "Best arrangement of BIPV surfaces for future NZEB districts while considering urban heat island effects and the reduction of reflected radiation from solar façades." Renewable Energy 160 (2020): 686-697.

[17] Shah, Rakibuzzaman, et al. "A review of key power system stability challenges for large-scale PV integration." Renewable and Sustainable Energy Reviews 41 (2015): 1423-1436.

[18] Ellis, Bryan E., Nathaniel Pearre, and Lukas Swan. "Power ramp rates and variability of individual and aggregate photovoltaic systems using measured production data at the municipal scale." Solar Energy 220 (2021): 363-370.

[19] Eltawil, Mohamed A., and Zhengming Zhao. "Grid-connected photovoltaic power systems: Technical and potential problems-A review." Renewable and sustainable energy reviews 14.1 (2010): 112-129.

[20] Gandhi, Oktoviano, et al. "Review of power system impacts at high PV penetration Part I: Factors limiting PV penetration." Solar Energy 210 (2020): 181-201.

[21] Lu Ping, Wang Xin, Li Yutong et al. "Benchmark model construction of district building energy demand forecast--A case of public building in Shenzhen" Journal Heating Ventilating and Airconditioning, 12 (2015): 14-21.

[22] Xu, Lijie, et al. "Annual analysis of a multi-functional BIPV/T solar wall system in typical cities of China." Energy 197 (2020): 117098 .

[23] Mohajeri, N., Perera, A. T. D., Coccolo, S., Mosca, L., Le Guen, M., \& Scartezzini, J. L. (2019). Integrating urban form and distributed energy systems: Assessment of sustainable development scenarios for a Swiss village to 2050. Renewable Energy, 143, 810-826.

[24] Ministry of industry and information technology of the people's Republic of China, Specification conditions of photovoltaic manufacturing industry, 2018.

[25] Al Garni, Hassan Z., Anjali Awasthi, and Makbul AM Ramli. "Optimal design and analysis of grid-connected photovoltaic under different tracking systems using HOMER." Energy conversion and management 155 (2018): 42-57.

[26] Tumminia, G., et al. "Grid interaction and environmental impact of a net zero energy building." Energy Conversion and Management 203 (2020): 112228.

[27] Dias, L. P., et al. "City energy modelling-Optimising local low carbon transitions with household budget constraints." Energy Strategy Reviews 26 (2019): 100387. 